\title{
DAMPAK TEKNOLOGI INFORMASI TERHADAP AUDIT INTERNAL
}

\author{
Arief Hidayat Tumanggor ${ }^{1}$ \\ Universitas Amir Hamzah \\ ariefhidayattumanggor.medan1985@gmail.com
}

\author{
T. M. Adriansyah ${ }^{2}$ \\ Universitas Amir Hamzah \\ $\underline{\text { tm411ca@gmail.com }}$
}

\begin{abstract}
ABSTRAK
Penelitian ini bertujuan untuk mengevaluasi peran teknologi informasi dan bagaimana pengaruhnya terhadap proses audit internal dalam organisasi. Penelitian ini juga menekankan pada tren global yang mengadopsi sistem TI (perangkat lunak / perangkat keras) dalam menghasilkan lingkungan yang lebih terkontrol dalam melaksanakan proses audit. Penelitian ini juga merupakan bagaimana TI mempengaruhi pengendalian internal (lingkungan pengendalian, penilaian risiko, kegiatan pengendalian, informasi dan komunikasi dan pemantauan) dan memberikan pedoman dan praktik terbaik dalam mengevaluasi teknik yang tersedia untuk secara efektif melakukan tugas audit internal. Ini juga membahas bagaimana teknologi, sistem informasi (IS) dan pemrosesan data elektronik (EDP) telah mengubah cara organisasi menjalankan bisnisnya, mempromosikan efisiensi operasional dan membantu pengambilan keputusan. Penelitian ini juga menyoroti banyak aspek risiko dan kontrol TI dan menyoroti apakah orang yang tepat mengawasi risiko TI sejauh yang seharusnya. Penelitian ini menunjukkan dampak konvergensi teknologi pada mekanisme pengendalian internal suatu perusahaan. Ini menekankan bahwa auditor juga memiliki tanggung jawab untuk memastikan bahwa tingkat tata kelola manajemen (komite audit dan dewan direksi) memahami risiko yang diterima oleh manajemen dan kewajiban yang berpotensi dialihkan kepada anggota dewan
\end{abstract}

Kata kunci: Audit internal, alat audit, audit TI, audit lanjutan 


\section{I. \\ PENDAHULUAN}

Audit internal dirancang untuk mengevaluasi keefektifan pengendalian internal suatu operasi dengan terlebih dahulu mengumpulkan informasi tentang bagaimana suatu unit beroperasi, mengidentifikasi titik-titik di mana kesalahan atau inefisiensi mungkin terjadi, dan mengidentifikasi pengendalian sistem yang dirancang untuk mencegah atau mendeteksi kejadian semacam itu. Kemudian, mereka menguji aplikasi dan kinerja kontrol tersebut untuk menilai seberapa baik mereka bekerja. Manajer harus secara rutin mengevaluasi kontrol dalam operasi departemen mereka dengan mengikuti proses yang sama. Komputer dan jaringan menyediakan sebagian besar informasi yang dibutuhkan untuk audit. Agar efektif, auditor harus menggunakan komputer sebagai alat audit, mengaudit sistem dan data otomatis, memahami tujuan bisnis sistem, dan memahami lingkungan tempat sistem beroperasi. Kegunaan penting lainnya untuk komputer dan jaringan oleh auditor adalah dalam administrasi audit. Dengan mencari kegunaan baru untuk komputer dan komunikasi, auditor meningkatkan kemampuan mereka untuk meninjau sistem dan informasi serta mengelola aktivitas mereka secara lebih efektif. Alat otomatis memungkinkan auditor untuk meningkatkan produktivitas individu dan fungsi audit. Dengan menyadari pentingnya lingkungan yang muncul dan persyaratan untuk melakukan tugas audit secara efektif, auditor harus mengenali alasan utama untuk menggunakan alat dan perangkat lunak audit, yang akan dieksplorasi lebih lanjut, di bagian selanjutnya. Alasan utamanya meliputi:

a. peningkatan untuk pribadi dalam pelajari keterampilan baru.

b. Tingkatkan pengambilan keputusan perusahaan menggunakan data yang ditingkatkan.

c. Meningkatkan efisiensi audit.

d. Kurangi tugas rutin untuk menyediakan lebih banyak waktu untuk analisis kreatif dan bisnis.

e. Menyediakan tata kelola transparansi organisasi yang lebih baik.

f. Identifikasi akar penyebab kuantitatif dari suatu masalah.

g. Kurangi penipuan dan penyalahgunaan.

h. Identifikasi penghematan dalam pemasok, pelanggan, sumber daya manusia, komputer, dan manajemen perusahaan.

Penelitian ini memberikan analisis singkat tentang area utama di mana perangkat lunak digunakan dalam audit, dampak teknologi pada profesi audit, dampak audit pada masalah bisnis dan teknologi yang muncul, dan contoh daftar produk teknologi informasi yang sering digunakan oleh auditor, dimana auditor sebagai sumberdaya manusia yang melaksanakan pemeriksaan harus memenuhi standar yang ditentuka (TM Adriansyah, 2019) 


\section{LITERATUR}

Untuk pemahaman yang lebih baik dan meninjau kembali studi sebelumnya tentang penerapan teknologi informasi untuk audit internal, tinjauan pustaka diuraikan sebagai dasar untuk mendefinisikan masalah penelitian dan tujuan dari penelitian ini. Survei literatur mencakup implikasi kuat dari kemajuan teknologi terhadap profesi audit internal dan manajemen audit.

\section{PERTANYAAN PENELITIAN}

Penelitian ini dilaksanakan untuk memberikan jawaban atas pertanyaan tentang “ sampai sejauh mana Internal Auditor memahami peran, dampak dan risiko teknologi informasi dalam melaksanaan audit. “

\section{METODOLOGI}

\section{Kerangka/Disain Penelitian}

Penelitian ini akan memberikan pemahaman awal untuk lebih memahami peran, dampak dan risiko TI terhadap auditor Pembahasan dalam penelitian menggunakan analisis desktiptif, dengan kerangka/disain penelitian dikembangkan seperti yang ditunjukkan pada Gambar dibawah ini :

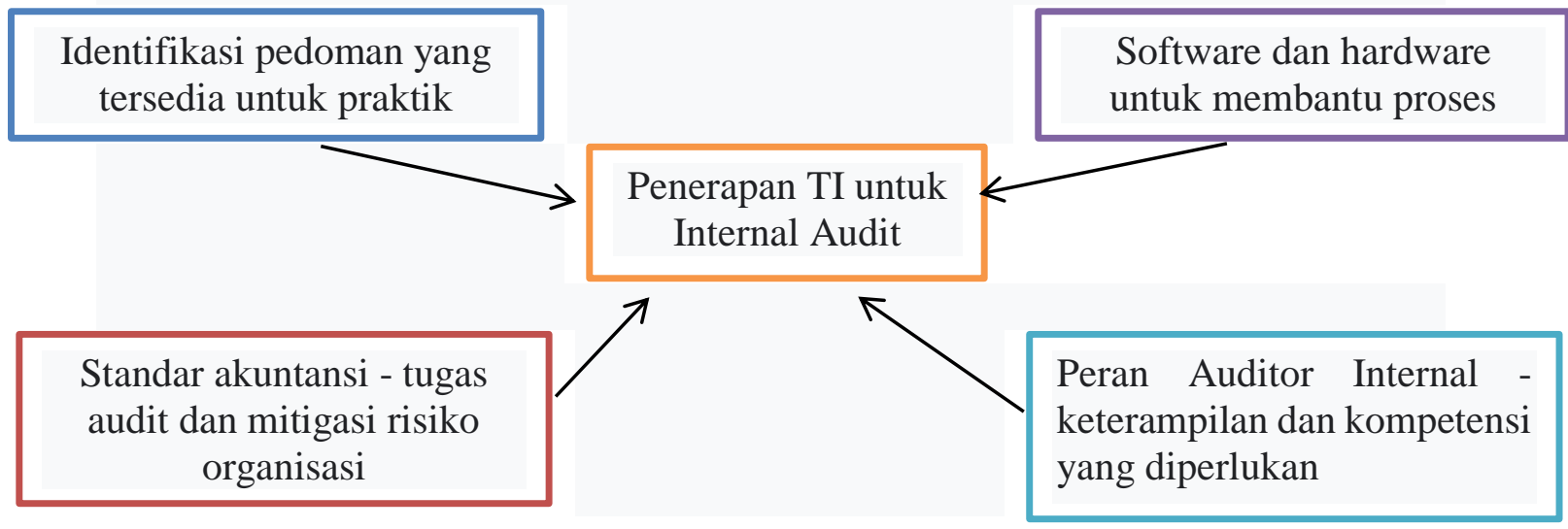

\section{Data}

Informasi dan data proyek penelitian dikumpulkan dari berbagai sumber data sekunder. Sumber data sekunder termasuk artikel jurnal yang diterbitkan di majalah dan diunduh dari Situs Web Internet termasuk Database Riset Host Emerald dan EBSCO. Mesin pencari Internet seperti Google, Lycos dan Yahoo juga 
menawarkan pencarian yang sangat baik untuk menemukan artikel online. Referensi lain juga dibuat tentang topik penelitian dari berbagai bab akuntansi dan buku teks yang relevan.

\section{PEMBAHASAN}

Penggunaan teknologi informasi dalam manajemen audit Manajemen audit bertugas menyediakan tenaga audit yang efektif, mengarahkan sumber daya audit untuk keuntungan maksimum organisasi, dan mematuhi undang-undang, peraturan, dan kebijakan mengenai audit. Ini melibatkan peninjauan proses, aktivitas, dan informasi yang mewakili risiko terbesar, merencanakan dan mengelola penugasan audit individu, memelihara catatan audit sebelumnya dan saat ini, mengarahkan dan menjadwalkan personel, dan berkomunikasi secara efektif dengan klien audit, manajemen senior, dan dewan direksi. Manajemen audit mencakup lebih banyak hal yang hanya menggunakan alat yang tepat, tetapi artikel ini mengupas terutama tentang alat dan teknik.

Memahami Analisis Risiko dan Manajemen Risiko. Ruang lingkup dan arah tujuan audit harus ditentukan dengan menilai area yang mewakili risiko terbesar bagi organisasi. Ada banyak pendekatan untuk analisis dan manajemen risiko. Idealnya analisis risiko akan dilakukan sebagai proses manajemen risiko di dalam organisasi dengan atau tanpa keterlibatan langsung dari audit internal. Jika manajemen risiko bukan merupakan proses manajemen formal, maka auditor harus menilai risiko dan manajemen risiko dan menemukan cara untuk berkomunikasi dengan manajemen untuk memastikan pandangan yang konsisten tentang risiko. Penilaian risiko adalah proses berulang dan hasil penilaian risiko harus dipelihara sedemikian rupa untuk memfasilitasi referensi dan pemutakhiran oleh auditor selama proyek audit berikutnya. Definisi audit internal, disetujui pada bulan Juni 1999, menunjukkan peran aktif auditor internal dalam manajemen risiko untuk organisasi mereka: Audit internal adalah kegiatan asurans dan konsultasi yang independen dan obyektif yang dirancang untuk menambah nilai dan meningkatkan operasi organisasi. Ini membantu organisasi mencapai tujuannya dengan membawa pendekatan yang sistematis dan disiplin untuk mengevaluasi dan meningkatkan efektivitas manajemen risiko, pengendalian, dan proses tata kelola. Kadang-kadang auditor dapat berfokus pada pengendalian bisnis dan mengabaikan fakta bahwa pengendalian ada untuk tujuan mengelola risiko. Auditor, juga, dapat mengejar pengurangan risiko daripada memahami ruang lingkup dan pentingnya manajemen risiko. Manajer di luar audit biasanya tidak menganggap tanggung jawab manajemen dalam kaitannya dengan pengendalian. Mereka memikirkan proses dan aktivitas yang mereka kelola, dan bagaimana mereka mengelola risiko. Jadi alat komunikasi penting bagi auditor adalah identifikasi dan penilaian risiko yang jelas dan dipahami. Manajer memahami risiko dan mungkin dapat menggambarkan risiko paling signifikan yang mereka kelola. Auditor dapat melengkapi daftar risiko manajer dengan mengajukan pertanyaan tentang jenis hal-hal yang diketahui auditor biasanya bisa salah. Umumnya lebih efektif untuk melanjutkan dari diskusi 
tentang ancaman dan risiko ke penilaian pengendalian daripada memulai dengan berbicara tentang pengendalian.

Daftar risiko yang diberikan oleh manajemen dan ditambah oleh auditor merupakan elemen pertama dari analisis risiko auditor. Langkah selanjutnya melibatkan penilaian kemungkinan eksposur akibat risiko dan biaya potensial. Untuk ini, auditor dapat menggunakan alat yang sederhana seperti spreadsheet atau database, atau dapat memilih sistem yang lebih kompleks yang mungkin diikat ke dalam sistem manajemen audit terintegrasi. Apapun pendekatan dan alat yang digunakan, penilaian risiko auditor harus dibagikan dengan manajemen, dan konsensus umum harus dicari untuk memastikan komunikasi yang efektif tentang tujuan, prioritas, dan ruang lingkup audit. Auditor juga memiliki tanggung jawab untuk memastikan bahwa tingkat tata kelola manajemen (komite audit dan dewan direksi) memahami risiko yang diterima oleh manajemen dan kewajiban yang berpotensi dialihkan kepada anggota dewan. Jika tata kelola dan manajemen eksekutif tidak memiliki pemahaman yang jelas tentang manajemen risiko dalam organisasi, tiga hasil kemungkinan besar:

a) Keputusan risiko akan dibuat pada tingkat organisasi yang terlalu rendah untuk cukup memahami dan memikul tanggung jawab atas konsekuensi potensial untuk risiko yang diterima.

b) Keputusan risiko tidak akan dikomunikasikan secara memadai kepada tata kelola dan manajemen eksekutif dan mereka tidak akan menyadari beberapa risiko yang diterima atas nama organisasi dan individu.

c) Sumber daya yang tidak memadai dapat disediakan untuk manajemen risiko di area kritis (misalnya, keamanan informasi) karena manajemen senior tidak menyadari potensi konsekuensi.

Memahami dan memantau lingkungan yang berubah. Audit juga dapat berubah terkadang perubahan signifikan. Misalnya, lima tahun yang lalu perdagangan elektronik Internet adalah item kecil di inventaris semesta audit - jika terdaftar sama sekali. Sekarang ini adalah item utama di sebagian besar inventaris audit tetapi masih belum terdaftar di beberapa. Masalah yang terkait dengan keamanan informasi, privasi, dan perdagangan elektronik yang aman, terutama melalui media Internet yang tidak aman, adalah item yang sangat penting bagi banyak organisasi. Dalam banyak kasus, auditor internal akan segera diminta untuk menunjukkan keahlian dalam mata pelajaran yang saat ini tidak dapat mereka jelaskan.

Memahami evaluasi pengendalian internal. Kontrol penilaian diri atau Control self assessment (CSA) adalah metodologi populer untuk mengidentifikasi dan mengevaluasi pengendalian internal. CSA memungkinkan pemilik bisnis dan operator untuk fokus pada eksposur risiko dan sarana untuk memitigasi, atau mengelola lebih baik, risiko tersebut. Seringkali auditor internal akan terbiasa dengan CSA dan dapat bertindak sebagai fasilitator diskusi kelompok untuk mengidentifikasi dan menilai pengendalian internal, mengatasi kekuatan dan kelemahan mereka, dan mendiskusikan peluang untuk perbaikan. Teknologi populer untuk CSA melibatkan perangkat keras dan perangkat lunak dengan 
perangkat interaktif untuk komunikasi kelompok dalam pertemuan tatap muka. Seorang fasilitator mengajukan pertanyaan atau pernyataan kepada peserta, dengan serangkaian pilihan jawaban - biasanya diproyeksikan pada layar besar. Perangkat lunak membuat grafik hasil dari respon papan tombol, dan memproyeksikannya untuk dilihat oleh kelompok. Beberapa sistem menyediakan respons teks tidak terstruktur. Tanggapan biasanya anonim untuk mendorong kejujuran dan keterbukaan. Umpan balik segera adalah fitur utama dari sistem CSA. (Tumanggor, 2020).

Memahami perencanaan dan penjadwalan audit. Perencanaan audit bersifat strategis dan taktis. Inventaris alam semesta audit, prioritas audit, dan ketersediaan sumber daya audit memberikan masukan untuk jadwal audit strategis. Perencanaan taktis dilakukan untuk setiap proyek audit.

Perencanaan Audit Strategis. Faktor penjadwalan strategis bersifat logis dan logistik. Misalnya, masalah yang diketahui dengan metode pengembangan sistem, kontrol perubahan sistem dan program, atau kontrol akses harus ditangani sebelum auditor mempertimbangkan untuk terlibat dalam proyek pengembangan sistem individu atau tinjauan sistem aplikasi. Kelemahan dalam area kontrol utama seperti manajemen akses dan kontrol perubahan juga dapat memengaruhi keandalan informasi apa pun yang digunakan oleh auditor dan dapat memengaruhi ruang lingkup dan waktu yang diperlukan untuk menilai dan menguji kontrol. Dalam melakukan audit sistem, informasi, atau proses bisnis di area di mana auditor mengetahui atau mencurigai adanya kelemahan pengendalian utama, pendekatan audit dapat ditingkatkan dengan awalnya menargetkan informasi untuk pengambilan dan analisis yang akan memberikan bukti konsekuensi dari kelemahan pengendalian. Pendekatan ini dapat menghasilkan bukti konsekuensi dari pengendalian yang lemah dan mungkin merupakan penggunaan waktu auditor yang lebih efektif daripada melakukan analisis ekstensif terhadap sistem dan lingkungan pengendalian untuk mengidentifikasi dan menilai pengendalian.

Perencanaan audit taktis. Alat perangkat lunak dapat membantu dalam menilai keterampilan auditor yang tersedia dan menugaskan orang yang tepat untuk mengaudit tim proyek. Perangkat lunak penjadwalan audit harus mendukung penugasan auditor dengan keterampilan kritis yang diperlukan dalam proyek audit, dan memungkinkan auditor tersebut untuk melanjutkan ke proyek lain setelah tugas mereka selesai, bahkan jika audit belum selesai. Perangkat lunak tersebut juga harus menilai dampak perubahan jadwal dan prioritas, kompensasi untuk penugasan khusus, dan memperluas dampak pembengkakan jadwal ke proyek lain yang tersisa dalam jadwal.

Mengubah peran auditor : Penggunaan alat dan teknik audit berbantuan komputer (CAATT). Karena alat audit tumbuh lebih kuat dan canggih, alat tersebut juga menjadi lebih mudah dipelajari dan digunakan. Tetapi mereka juga harus menyesuaikan diri dengan lingkungan yang kompleks dan selalu berubah. Fitur 
perangkat lunak audit dapat dengan mudah berbenturan dengan fitur perangkat lunak lain di komputer atau jaringan, dan harus dikelola dengan hati-hati. Sebagai alat audit menjadi lebih kuat, auditor dapat menggunakan fitur atau layanan yang disediakan dalam perangkat lunak yang memerintahkan sejumlah besar sumber daya sistem (memori, siklus pemrosesan, bandwidth komunikasi, dan penyimpanan) dan bersaing dengan pengguna lain dari sumber daya tersebut. Misalnya, auditor dapat meminta akses ke file dengan program yang akan memeriksa setiap rekaman dalam file dan mungkin mengunci pengguna lain hingga prosesnya selesai. Pemrosesan juga dapat memerlukan ruang penyimpanan jaringan dalam jumlah besar pada saat persediaan terbatas dan dapat menyebabkan server "mogok". Penting untuk menjadwalkan pemrosesan seperti itu pada saat pengguna sistem lain tidak akan tertunda atau dicegah untuk melakukan pekerjaan mereka. Sebagai alternatif, banyak organisasi audit melakukan analisis audit mereka menggunakan file yang disalin atau diarsipkan dari file produksi langsung. CAATT juga mungkin besar, kuat, atau cukup khusus untuk memerlukan server khusus untuk tujuan audit. Server mungkin diperlukan untuk mendukung situs web audit, atau hanya untuk memastikan independensi dan keamanan yang diperlukan oleh fungsi audit. Dan, sebagaimana dibuktikan dengan daftar perangkat lunak yang dilampirkan pada dokumen ini, ada lebih banyak alat yang tersedia daripada jumlah waktu yang mungkin harus dipelajari auditor untuk menggunakan alat tersebut. Jadi kebutuhan akan spesialis perangkat lunak untuk mendukung audit internal semakin meningkat meskipun perangkat lunak tersebut semakin mudah digunakan.

Memahami pemantauan pengendalian internal berkelanjutan. Pemantauan berkelanjutan dalam sistem dan jaringan akan menjadi produk sampingan dari meningkatnya permintaan untuk akses langsung dan berkelanjutan ke informasi yang dapat diandalkan oleh manajemen, pemilik, investor, dan regulator organisasi dari semua jenis dan ukuran. Ketersediaan komunikasi elektronik yang meluas mendorong permintaan akan informasi yang andal dan layanan jaminan terkait. Sistem akuntansi terintegrasi dengan cepat menjadi hal biasa, dan akan segera menjadi dasar yang mapan untuk ekspektasi ketepatan waktu dalam ketersediaan informasi keuangan. Pelaporan keuangan segera dan ketersediaan informasi untuk perbandingan dan analisis menjadi produk sampingan dari aplikasi terintegrasi di semua bidang bisnis dan industri yang menggabungkan informasi operasional dan keuangan dalam database dan pelaporan manajemen terintegrasi. Munculnya standar seperti Extensible Markup Language (XML) dan Extensible Business Reporting Language (XBRL) terkait juga akan membantu mempercepat laju peningkatan ekspektasi untuk ketersediaan informasi dan jaminan terkait integritasnya. Seperti yang ditunjukkan sebelumnya, kemajuan dalam pemantauan dan analisis informasi sedang dipercepat baik dengan meningkatnya permintaan akan informasi yang tepat waktu dan akurat, dan dengan kemajuan teknologi yang berkontribusi pada kecerdasan, kemampuan, dan ketepatan waktu sistem pemantauan dan analisis. Sistem pemantauan berkelanjutan bukanlah hal baru, tetapi mereka juga tidak dapat dianggap meluas saat ini. Namun kemajuan dalam sistem dan meningkatnya ekspektasi ketersediaan informasi akan memastikan 
bahwa sistem pemantauan dan audit yang berkelanjutan akan menjadi aturan, bukan pengecualian dalam waktu dekat.

Memahami pelaporan audit elektronik. Beberapa alat audit saat ini menyediakan penghubung otomatis antara pekerjaan yang dilakukan, informasi yang dikumpulkan, penilaian auditor, dan informasi yang digunakan dalam atau mendukung laporan audit. Makalah kerja yang cerdas dapat mencatat jawaban dalam Kuesioner Pengendalian Internal (ICQ) yang menunjukkan kelemahan aktual atau potensial dan secara otomatis menyiapkan bagian dalam laporan audit untuk mendokumentasikan kelemahan dan / atau penyelesaian masalah. Pelaporan audit juga, secara otomatis dapat memberikan informasi tentang bagian-bagian audit yang dilakukan oleh auditor individu setelah selesai sehingga supervisor audit akan mengetahui status proyek audit yang sedang berlangsung. Pelaporan semacam itu juga akan memungkinkan supervisor untuk berkonsentrasi pada proses audit yang menunjukkan masalah dan / atau menyediakan sumber daya tambahan di area yang terlambat dari jadwal. (Tumanggor, 2020). Laporan audit dapat dengan mudah berisi tautan ke dokumen kertas kerja, lembar kerja, grafik, atau informasi lain yang akan diperbarui secara otomatis saat data berubah. File laporan dapat dibagikan oleh anggota tim audit dan manajemen dengan menerapkan kontrol sederhana atas akses seperti akses hanya-baca bagi mereka yang tidak berwenang untuk mengubah file. Laporan audit dapat didistribusikan dalam format elektronik melalui email, transfer file, atau situs web audit. Dalam kasus seperti itu, auditor harus memastikan keamanan, kerahasiaan, dan kontrol akses yang sesuai untuk laporan tersebut. Teknologi enkripsi berkembang pesat dan akan menjadi mekanisme standar untuk integritas pesan elektronik, otentikasi pengirim dan penerima, dan kontrol akses.

\section{KESIMPULAN}

1. Belum adanya aplikasi teknologi informasi yang spesifik dan terintegrasi yang dapat digunakan oleh auditor secara keseluruhan dalam melaksanakan perannya sebagai auditor internal. Penting untuk diperhatikan bahwa tidak ada model generik untuk perangkat teknologi yang dapat diterapkan di semua organisasi. Penting juga untuk mengenali ketergantungan yang semakin meningkat pada teknologi untuk menyelesaikan dan / atau mendukung hampir semua aktivitas audit.

2. Topik tentang penggunaan teknologi informasi terus meningkat dari kumpulan pengetahuan dan keterampilan profesional auditor. Sementara latar belakang pemahaman dan penggunaan teknologi informasi oleh auditor penting dalam memahami perkembangan dan dinamika dalam proses pemeriksaan internal dalam suatu organisasai / perusahaan, hal itu tidak banyak gunanya bila auditor dalam emlaksanakan perannya tidak memiliki pengetahuan terbarukan dalam teknologi informasi yang berkelanjutan untuk mendukung perannya sebagai auditor internal.

3. Penggunaan alat teknologi audit yang efektif sangat penting untuk keberhasilan aktivitas audit, tetapi hanya satu langkah untuk memahami perubahan teknologi yang ditimbulkan dalam bisnis dan profesi audit. Teknologi yang muncul akan 
terus mengubah bentuk dan pendekatan terhadap kontrol bisnis, dan pendekatan serta teknik audit harus berubah sesuai dengan itu.

4. Peran penting lainnya bagi auditor, dan profesi audit, adalah untuk mendorong dan mendukung upaya penyediaan sistem dan teknologi baru untuk meningkatkan fitur pemantauan/pemeriksaan dan tidak menganggapnya sebagai beban lebih atas kegiatan/proses sebagai auditor internal, atau menjadikannya sebagai elemen yang berkontribusi terhadap penurunan kinerja. Peran penting auditor tidak hanya untuk memahami dan berubah dengan teknologi, tetapi juga menjelaskan efek dari perubahan tersebut kepada orang lain. Dan terakhir, penting juga untuk diingat pentingnya kontak interpersonal ( antarpribadi ) dalam audit karena keyboard dan email ( computer/teknologi informasi ) tidak akan pernah menggantikan kebutuhan akan keterampilan interpersonal, sebagai sumberdaya manusia dalam sebuah organisasi/perusahaan (TM Adriansyah, 2019).

5. Bahwa tidak ada model umum untuk perangkat teknologi khususnya teknologi informasi yang dapat diterapkan untuk semua organisasi, oleh karena itu penting untuk mengenali sampai sejauh mana ketergantungan pada teknologi informasi dapat menyelesaikan dan / atau mendukung hampir semua aktivitas audit.

\section{UCAPAN TERIMA KASIH}

Penulis mengucapkan terima kasih kepada semua pihak yang telah memberikan dukungan terhadap penulisan artikel ilmiah ini, khususnya kepada Dekan Fakultas Ekonomi Universitas Amir Hamzah.

\section{REFERENCES}

ACL Service Ltd, https://www.wegalvanize.com/audit-management/

Brazel JF (2005). A measure of perceived auditor ERP systems expertise : Development, assessment, and uses. https://www.emerald.com/insight/content/doi/10.1108/0268690051060610 $\underline{0 / f u l l / h t m l \text { ?skipTracking=true }}$

Chen Y (2004). Continuous Auditing Using A Strategic System Approach. https://www.emerald.com/insight/content/doi/10.1108/eb001410/full/html ?skipTracking=true

Coderee DG (1993). Automating the audit function https://medium.com/information-technology-and-internal-auditing/https$\underline{\text { medium-com-it-and-internal-auditing-taremwa256-7982e3a3456b }}$ 
Deloitte, Touche (1996). The Current Impact of Information Technology on Internal Auditing Departments. http://www.theiia.org/ecm/tech.cfm?doc_id=859

Debreceny R, Lee SL, Neo W, Toh JS (2005) Employing generalized audit software in the financial services sector. http://www.emeraldinsight.com/Insight/Articles/0210909604.html

Goodwin J (2004). A comparison of internal audit in the private and public sectors. http://www.emeraldinsight.com/Insight/Articles/0251314604.html

Grand CL (2001). Use of Information Technology in Audit Management. http://www.theiia.org/itaudit/index.cfm?fuseaction=forum\&fid=345

Hadden LB, DeZoort FT, Hermanson DR (2003). IT Risk Oversight: The Roles of Audit Committees, Internal Auditors, and External Auditors. http://www.findarticles.com/p/articles/we_m11/is_4_59/ai_d02a7860

Harrison MJ, Datta P (2007). An empirical assessment of user perceptions of feature versus application level usage. Commun Assoc Inf Syst. 20: 300321

Jackson RA (2004). Get the most out of audit tools www.findarticles.com/p/articles/mi_m4153/is_4_61/ai_n6169113

James L. Bierstaker JL, Burnaby P, Thibodeau J (2001). The impact of information technology on the audit process: an assessment of the state of the art and implications for the future. http://www.emeraldinsight.com/Insight/Articles/0382201206.html

Jayalakshmy R, Seetharaman A, Khong TW (2005). The changing role of the auditors.

http://www.emeraldinsight.com/Insight/Articles/057785604.html

Khadaroo I (2005). Corporate reporting on the Internet: some implications for the auditing http://www.emeraldinsight.com/Insight/Articles/0665856604.html

Kim HJ, Mannino M, Nieschwietz RJ (2009). Information technology acceptance in the internal audit profession: Impact of technology features and complexity. Int. J. Accounting Inf. Syst. 10(4): 214-228

Lanza RB (2004). Can Excel Double as Audit Software. http://www.theiia.org/itaudit/index.cfm?fuseaction=forum\&fid=5483 
Pathak J (2005). Risk manage, internal controls and organizational vulnerabilities. http://www.emeraldinsight.com/Insight/Articles/0213406604.html

Searcy DL, Woodroof JB (2003). Continuous Auditing: Leveraging Technology. http://www.emeraldinsight.com/Insight/Articles/0619806601.html

Shaikh JM (2004) E-commerce impact: emerging technology electronic auditing http://www.emeraldinsight.com/Insight/Articles/0415560199.html

TM Adriansyah. (2019). Pengantar Manajemen Sumber Daya Manusia / ISBN 978623-7160-80-9. Medan: Perdana Publishing.

Tumanggor, A. H. (2020). Faktor Determinan yang Mempengaruhi Implementasi RBIA ( Risk Based Internal Auditing ) pada Pemerintah Daerah Kabupaten Langkat. Jurnal Uhamzah, ISSN 2088-7299, Vol.10 No.19, Maret 2020, https://unhamzah.ac.id/volume-10-nomor-19-maret-2020/, 86-98. 